\title{
Characterization of variants in the promoter of BZLF1 gene of EBV in nonmalignant EBV-associated diseases in Chinese children
}

\author{
Yingkang Jin', Zhengde Xie*2, Gen Lu², Shuang Yang³ and Kunling Shen*1
}

\begin{abstract}
Background: Diseases associated with Epstein-Barr virus (EBV) infections, such as infectious mononucleosis (IM), EBVassociated hemophagocytic lymphohistiocytosis (EBV-HLH) and chronic active EBV infection (CAEBV) are not rare in Chinese children. The association of type 1 or type 2 EBV and variants of the EBV BZLF1 promoter zone (Zp) with these diseases is unclear.

Results: The objective of this study was to investigate the relationship between EBV genotypes (Zp variants and EBV type 1 and 2) and the clinical phenotypes of EBV-associated diseases in Chinese children. The Zp region was directly sequenced in $206 \mathrm{EBV}$-positive DNA samples from the blood of patients with IM, EBV-HLH, CAEBV, and healthy controls. Type 1 or type 2 EBV was examined by PCR for EBNA2 and EBNA3C subtypes. Four polymorphic Z $p$ variants were identified: Zp-P, Zp-V3, Zp-P4 and Zp-V1, a new variant. The Zp-V3 variant was significantly associated with CAEBV ( $P \leq$ 0.01). The frequency of co-infection with Zp variants was higher in patients with CAEBV and EBV-HLH, compared with $I M$ and healthy controls, mostly as Zp-P+V3 co-infection. Type $1 \mathrm{EBV}$ was predominant in all categories (81.3-95\%) and there was no significant difference in the frequency of the EBV types 1 and 2 in different categories $(P>0.05)$.
\end{abstract}

Conclusions: Type 1 EBV and BZLF1 Zp-P of EBV were the predominant genotypes in nonmalignant EBV associated diseases in Chinese children and Zp-V3 variant may correlates with the developing of severe EBV infection diseases, such as CAEBV and EBV-HLH.

\section{Background}

Epstein-Barr virus (EBV) is a member of the Lymphocryptovirus genus, Gammaherpesvirinae subfamily of the Herpesviridae family of viruses. This virus is associated with a wide variety of diseases, both benign and malignant, which ubiquitously infect humans and persist for the lifetime of the individual. During its life cycle, EBV has latent and productive (lytic) phases. The latent phase maintains the virus long-term in its host and can lead to the productive phase where virus is reactivated and produced allowing it to be transmitted. During the two phases, EBV expresses a set of viral gene products in its life cycle and some of these genes were proved to possess the potential to cause changes in the interactions between the virus and the host's immune system $[1,2]$.

*Correspondence: zhengde_xie@hotmail.com, kunlingshen@yahoo.cn

2 Department of Virology, Beijing Children's Hospital, The Capital Medical University, Beijing 100045, China

Full list of author information is available at the end of the article
The biology and pathogenesis of EBV has been the focus of many studies but the clinical management of the disease is poorly understood. Whether certain EBV genotypes are involved in the pathogenesis of specific EBVrelated diseases has been the subject of investigation in recent years. Several viral variants can be distinguished according to polymorphisms in EBV genes, such as EBV nuclear antigen (EBNA) and BZLF1, a potent regulator of the switch from latency to lytic phases encoded by the EBV BamHI fragment Z. EBV genotypes can be categorized as type 1 or type 2 on the basis of marked allelic polymorphisms within the EBNA2, 3A, 3B, and $3 \mathrm{C}$ genes $[3,4]$. Both EBV types have been detected in immunocompromised and immunocompetent hosts but type 1 EBV is predominant in Asian nasopharyngeal carcinoma and has a greater potential to transform $B$ lymphocytes than EBV type 2. Type 2 EBV, on the other hand, enters the lytic cycle more readily than type 1 EBV [5-7]. Sequence diversity of the BZLF1 gene promoter zone 
(Zp) (from -221 to +12 , with respect to the transcription start site of BZLF1) have also been identified and variants are differentially distributed among malignant and nonmalignant cells $[8,9]$.

Childhood EBV infection is typically asymptomatic but can also induce three types of non-malignant disorders, including infectious mononucleosis (IM), EBV-associated hemophagocytic lymphohistiocytosis (EBV-HLH) and chronic active EBV infection (CAEBV). Certain linkages exist between these diseases where IM, usually a benign self-limiting disease, can develop to EBV-HLH and CAEBV in some patients. Likewise, EBV-HLH progresses very rapidly and becomes a life-threatening disease without immunosuppressive therapy, which occurs during the process of CAEBV sometimes or in association with fulminant IM[10-12]. CAEBV is characterized by chronic or recurrent IM-like symptoms persisting over a long period of time and has a high likelihood of developing into EBV related malignant diseases, such as T/NK cell lymphomas, with a high fatality rate [13-15]. Thus, this study aimed to investigate the association of BZLF1 Zp variants and type 1 and type 2 EBV and to explore the relationship between these EBV genotypes and clinical phenotypes of EBV-associated diseases in Chinese children.

In this study, EBV DNA from blood samples of 206 patients with IM, EBV-HLH, CAEBV, and healthy controls was examined by PCR for EBNA2 and EBNA3C subtypes (EBV type 1 and type 2 ) and Zp variants. This case-control study is the first investigation to explore the association between EBV subtypes and BZLF1-Zp variants and EBV infection in the China children population.

\section{Results}

\section{Definition of type 1 or/and type 2 EBV in patients with EBV} infection

The frequency of type 1 or type 2 EBV infection was determined for all samples (Table 1). Collectively, type 1 EBV was present in 190 of 206 samples (92.2\%) and type 2 EBV was found in 12 samples (5.8\%). Among all patients, there was no significant difference $(P>0.05)$ in the frequency of the EBV type 1 and type 2 between categories.
The remaining four cases (1.9\%) displayed co-infection with both type 1 and type $2 \mathrm{EBV}$ and were all from the CAEBV group.

\section{Zp variants in EBV infected children}

Sequence differences identified within the major regulatory $\mathrm{Zp}$ domains (nucleotides -211 to +12 ) of EBV infected individuals can be grouped into four variant forms (Figure 1). Zp-P group sequences are identical to the EBV prototype strain, B95.8. Zp-V3 and Zp-V4 variants have been previously described by Gutierrez et al. [8]. Zp-V3 group sequences differ from Zp-P at three positions: -100 (TTG), -106 (ATG), and -141 (ATG); while $\mathrm{Zp}-4$ sequences are characterized by same three substitutions of the $\mathrm{Zp}-\mathrm{V} 3$ variant in addition to a $\mathrm{T}$ to $\mathrm{C}$ substitution at position -196. A new $\mathrm{Zp}$ variant was identified and named Zp-V1 and differs from Zp-P by a single substitution at position -196 (TTC). As shown in Table 2, The distribution of $\mathrm{Zp}$ subtypes involved all co-existence variants-IM included $\mathrm{P}(\mathrm{n}=61), \mathrm{V} 3(\mathrm{n}=3), \mathrm{V} 1(\mathrm{n}=4)$, $V 4(n=6), P+V 1(n=6), P+V 3(n=2), P+V 4(n=5)$; EBVHLH included $\mathrm{P}(\mathrm{n}=23), \mathrm{V} 3(\mathrm{n}=8), \mathrm{V} 4(\mathrm{n}=1), \mathrm{P}+\mathrm{V} 3(\mathrm{n}=$ $12), P+V 4(n=2)$; CAEBV included $P(n=6), V 3(n=14)$, $\mathrm{P}+\mathrm{V} 3(\mathrm{n}=12)$; controls included $\mathrm{P}(\mathrm{n}=29), \mathrm{V} 3(\mathrm{n}=1)$, $\mathrm{V} 1(\mathrm{n}=3), \mathrm{V} 4(\mathrm{n}=4), \mathrm{P}+\mathrm{V} 1(\mathrm{n}=1), \mathrm{P}+\mathrm{V} 4(\mathrm{n}=2)$. We found that $\mathrm{Zp}-\mathrm{P}$ variant was the dominant genotype found in all infection categories, except a relatively rare diseaseCAEBV, indicating that it was the primary variant of EBV circulating in China. The $\mathrm{Zp}-\mathrm{V} 3$ variant was the dominant genotype in CAEBV cases $(P \leq 0.01)$ and relatively high in EBV-HLH cases. The Zp-V1 variant, however, was only found in IM and control cases, while the V4 variant was not detected in any CAEBV cases.

\section{Co-existence of $\mathrm{Zp}$ variants and EBV subtypes}

As shown in Table 3, the incidence of co-existence of $\mathrm{Zp}$ variants (Figure 2) in HLH (30.4\%) and CAEBV (37.5\%) cases was higher than for both IM (14.8\%) and control cases $(7.5 \%)$. Interestingly, the $\mathrm{Zp}$ - $\mathrm{P}$ variant was present in every co-existence case that harbored two $\mathrm{Zp}$ variants. $\mathrm{Zp}-\mathrm{P}+\mathrm{V} 1$ variants were only detected in IM and control categories, whereas $\mathrm{Zp}-\mathrm{P}+\mathrm{V} 3$ variants were predominant

\section{Table 1: The frequency of EBV types 1 and 2 in each EBV-related disease group}

\begin{tabular}{|c|c|c|c|}
\hline \multirow[t]{2}{*}{ Groups } & \multicolumn{3}{|c|}{ EBV subtypes (n/N) } \\
\hline & Type 1 & Type 2 & Type 1 + Type 2 \\
\hline $\mathrm{IM}(\mathrm{n}=88)$ & $94.3(83 / 88)$ & $5.7(5 / 88)$ & 0 \\
\hline HLH $(n=46)$ & $93.4(43 / 46)$ & $6.6(3 / 46)$ & 0 \\
\hline CAEBV $(n=32)$ & $81.3(26 / 32)$ & $6.2(2 / 32)$ & $12.5(4 / 32)$ \\
\hline Controls $(n=40)$ & $95.0(38 / 40)$ & $5.0(2 / 40)$ & 0 \\
\hline Total $(n=206)$ & $92.2(190 / 206)$ & $5.8(12 / 206)$ & $1.9(4 / 206)$ \\
\hline
\end{tabular}




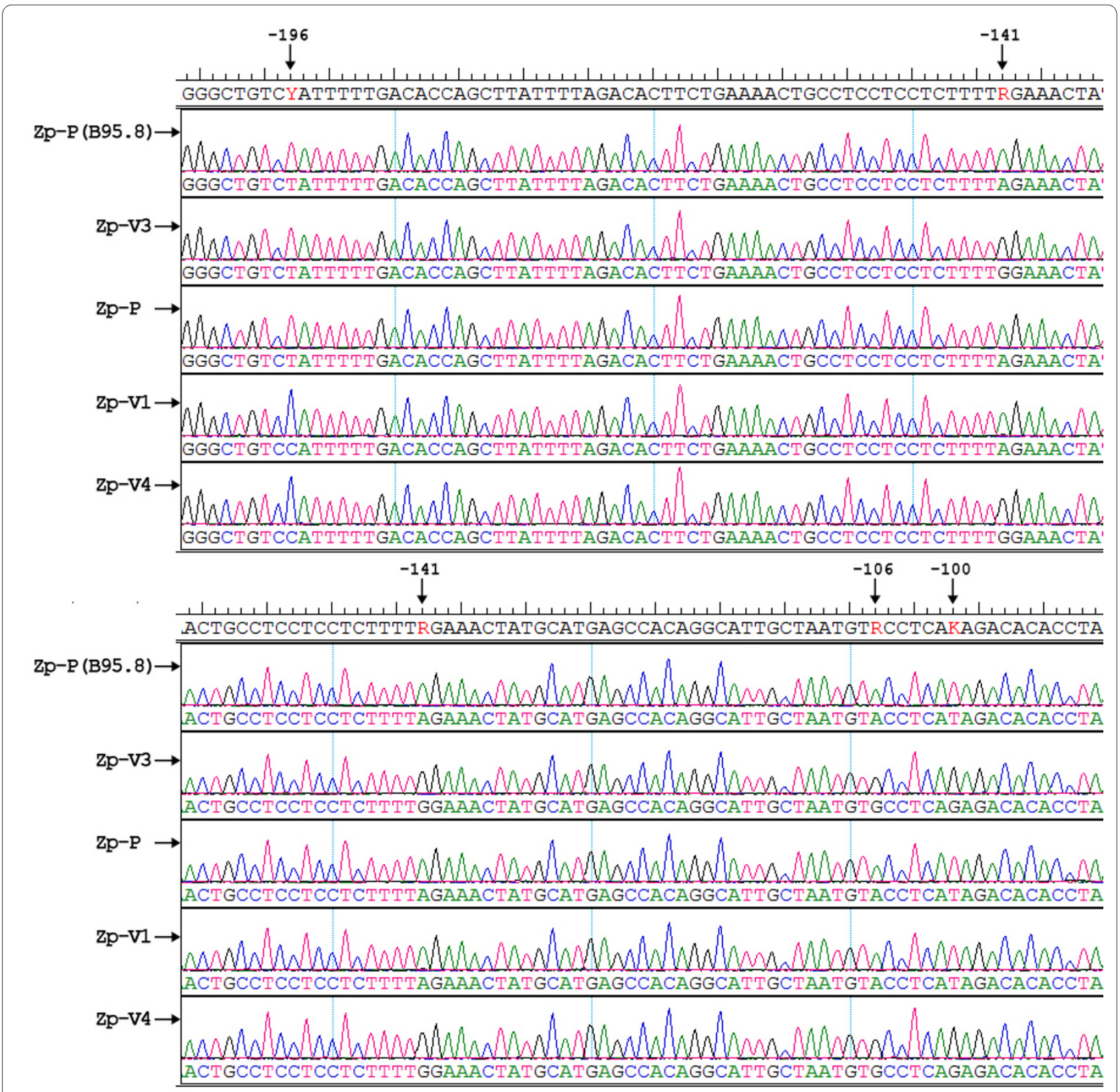

Figure 1 DNA sequences obtained for four EBV BZLF1 gene promoter zone (Zp) variants compared with the B95.8 prototype sequence. POsitions relative to the transcription start site are indicated.

in CAEBV and HLH samples. The four type $1+2 \mathrm{EBV}$ coinfection cases detected in the CAEBV group all contained $\mathrm{Zp}-\mathrm{P}+\mathrm{V} 3$ variants.

\section{Discussion}

This case-control study is the first investigation to explore the association between EBV subtypes and BZLF1-Zp variants and EBV infection in the China children population. In this study, statistical analysis determined that differences in the distribution of $\mathrm{Zp}$ variants were significant in the four patient categories. The frequency of the $\mathrm{Zp}-\mathrm{V} 3$ variant in the CAEBV group was statistically higher than for other categories $(P \leq 0.01)$, while $\mathrm{Zp}-\mathrm{P}$ was predominant in all categories except CAEBV. This suggests that the $\mathrm{Zp}-\mathrm{P}$ variant EBV was the most common variant found in China and that infection by $\mathrm{Zp}-\mathrm{V} 3$ is strongly correlated to CAEBV. The $\mathrm{Zp}-\mathrm{V} 3$ variant is significantly associated with malignancy in both immunocompetent and immunocompromised patients $[8,9]$ and the higher frequency of the $\mathrm{Zp}-\mathrm{V} 3$ vari- 
Table 2: The frequency of EBV BZLF1 gene promoter zone (Zp) variants in each EBV-related disease group."

\begin{tabular}{lllll}
\hline $\begin{array}{l}\text { Zp-variant } \\
\text { \%(n/N) }\end{array}$ & $\begin{array}{l}\text { IM } \\
(\mathbf{n = 8 8})\end{array}$ & $\begin{array}{l}\text { HLH } \\
(\mathbf{n = 4 6 )}\end{array}$ & $\begin{array}{l}\text { CAEBV } \\
(\mathbf{n = 3 2 )}\end{array}$ & $\begin{array}{l}\text { Controls } \\
(\mathbf{n = 4 0 )}\end{array}$ \\
\hline P & $84.1(74 / 88)$ & $80.4(37 / 46)$ & $56.3(18 / 32) \triangle$ & $85.0(34 / 40)$ \\
V3 & $5.7(5 / 88)$ & $43.5(20 / 46) \triangle$ & $81.3(26 / 32) \triangle$ & $2.5(1 / 40)$ \\
V4 & $12.5(11 / 88)$ & $6.5(3 / 46)$ & 0 & $15.0(6 / 40)$ \\
V1 & $11.4(10 / 88)$ & 0 & 0 & $10.0(4 / 40)$ \\
\hline
\end{tabular}

"The distribution of Zp subtypes involved all co-existence variants-IM included $P(n=61), V 3(n=3), V 1(n=4), V 4(n=6), P+V 1(n=6), P+V 3(n$

$=2), P+V 4(n=5)$; EBV-HLH included $P(n=23), V 3(n=8), V 4(n=1), P+V 3(n=12), P+V 4(n=2) ; C A E B V$ included $P(n=6), V 3(n=14), P+V 3(n=$

12); controls included $P(n=29), V 3(n=1), V 1(n=3), V 4(n=4), P+V 1(n=1), P+V 4(n=2)$

$\triangle(P \leq 0.01)$ vs other groups

ant in CAEBV patients observed in the current study suggests that CAEBV is more likely an entity of premalignancy. Similarly, the Zp-V4 variant was also identified in this study and was most associated with IM and healthy control cases. Zp-V1 was identified as a novel variant and was detected in $10 \mathrm{IM}$ and health control cases but not in CAEBV and EBV-HLH. The absence or low level of ZP-V1 and Zp-V4 in CAEBV and HLH reflects a less severe pathogenesis than for the $\mathrm{Zp}-\mathrm{V} 3$ variant which may enhance the tumorigenicity of EBV.

A novel $\mathrm{Zp}$ variant that differed from $\mathrm{Zp}-\mathrm{P}$ by one substitution at position -100 (TTG) was detect in this study in only one patient with EBV-HLH. Due to the infrequent isolation of this variant, we did not include this data in correlations with disease. Previously described $\mathrm{Zp}$ variants, Zp-PV, Zp-V1-104, Zp-V1-105 or Zp-V1-119 $[9,16]$ were not detected in any patient samples. Although it may be chance that these isolates were not detected, specific ethnic groups and geographical restrictions are likely to contribute to the narrow distribution of variants observed in the current study. The detection of different new variants suggests that the accumulation of viral mutations may contribute to the variations observed within the host during virus persistence.

Similar to other studies that reported that type 1 EBV was predominant in Asian nasopharyngeal carcinoma (86.5-96\%) $[17,18]$, the current study also found that type $1 \mathrm{EBV}$ was predominant in all four categories (81.3-95\%).
Also in agreement to these studies, type $2 \mathrm{EBV}$ infection was rarely detected (4-13.5\%). These findings suggest that the diagnosis of EBV types 1 and 2 in patients is not likely to be useful for predicting susceptibility to EBV-related diseases in Chinese children. Although patients with Zp$\mathrm{V} 4$ or $\mathrm{Zp}-\mathrm{V} 1$ variants were always type $1 \mathrm{EBV}$ carriers, this study did not confirm that $\mathrm{Zp}$ variants segregated by EBV type due to the extremely lower frequency of type 2 EBV in the Chinese study population. Gutierrez et al. had previously shown that the $\mathrm{Zp}-\mathrm{V} 3$ variant was exclusively associated with type $2 \mathrm{EBV}$ infection; however, the current study found that variant $\mathrm{Zp}-\mathrm{V} 3$ co-existed with both EBV types. Geographic regions, sample sizes or various diseases are like to result in these differences.

The prevalence of co-existence EBV Zp variants within the four categories studied ranged from 14.6 to $37.5 \%$. The majority of these co-existence viruses occurred in patients with CAEBV and EBV-HLH and always was found associated with $\mathrm{Zp}-\mathrm{P}$ and not other variants. It is likely that the majority of people are first infected with a more prevalent variant like $\mathrm{Zp}-\mathrm{P}$, the predominant variant found in this study, but does not rule out the possibility that new point mutations are likely to be arised during EBV replication of in its hosts from pre-existing variant. In this way, the balance of one pre-existing virus variant which could be controlled by its host, may be disturbed by a specific new variant. Thus, virus replication, tropism, or immune evasion in its hosts could be greatly

Table 3: The co-existence of EBV BZLF1 gene promoter zone (Zp) variants and EBV subtypes in each EBV-related disease study group.

\begin{tabular}{lllll}
\hline $\begin{array}{l}\text { Co-infection } \\
\%(\mathbf{n} / \mathbf{N})\end{array}$ & $\begin{array}{l}\text { IM } \\
(\mathbf{n}=\mathbf{8 8})\end{array}$ & $\begin{array}{l}\text { HLH } \\
\mathbf{( n = 4 6 )}\end{array}$ & $\begin{array}{l}\text { CAEBV } \\
(\mathbf{n = 3 2})\end{array}$ & $\begin{array}{l}\text { Controls } \\
(\mathbf{n}=\mathbf{4 0})\end{array}$ \\
\hline Zp-P+V1 & $6.8(6 / 88)$ & 0 & 0 & $2.5(1 / 40)$ \\
Zp-P+V4 & $5.7(5 / 88)$ & $4.3(2 / 46)$ & 0 & $5.0(2 / 40)$ \\
Zp-P+V3 & $2.3(2 / 88)$ & $26.1(12 / 46)$ & $37.5(12 / 32)$ & 0 \\
Total & $14.8(13 / 88)$ & $30.4(14 / 46)$ & $37.5(12 / 32)$ & $7.5(3 / 40)$ \\
\hline
\end{tabular}

${ }^{*}$ Four patients detected in CAEBV with both type 1 and type 2 co-infections were also presented with Zp-P and Zp-V3 co-exsistences. 


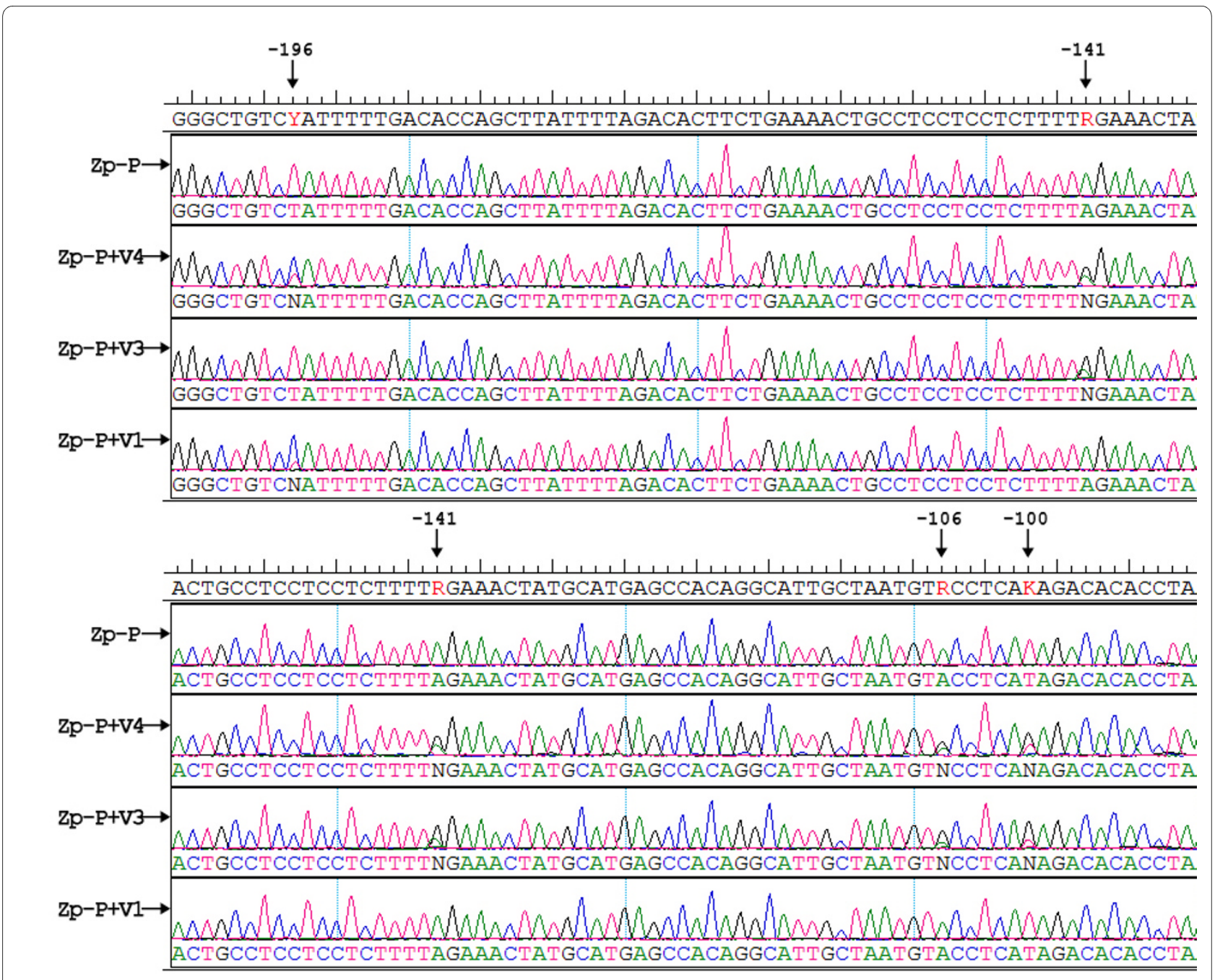

Figure 2 DNA sequences obtained for co-exisence of EBV BZLF1 gene promoter zone (Zp) variants compared with the B95.8 prototype sequence. Positions relative to the transcription start site are indicated.

enhanced after acquiring this new variant. As the $\mathrm{Zp}-\mathrm{V} 3$ variant was associated with severe diseases in this study, the $\mathrm{Zp}-\mathrm{V} 3$ type point mutations derived from $\mathrm{Zp}-\mathrm{P}$ are likely to be associated with a more invasive capacity than $\mathrm{Zp}-\mathrm{V} 1$ or $\mathrm{Zp}-\mathrm{V} 4$ variants. Taken together, superinfection by multiple strains of EBV, especially the presence of the $\mathrm{Zp}-\mathrm{V} 3$ variant, may be a contributing factor in the development of severe EBV infections in children. Thus, these findings may give some prospect to explore the differential distribution of $\mathrm{Zp}$ variants in susceptible populations and their association with severe or even fatal EBV diseases. A close dynamic follow-up on patients carrying EBV from an early stage of infection may help us understand how the host immune response allows such mutations to occur.
Just how an individual acquires such mixtures of $\mathrm{Zp}$ variants is unknown. This could occur by simultaneous acquisition or by the serial accumulation from exposure to different variant carriers. It seems implausible that such co-infections can be co-acquired from a carrier who was shedding multiple variants in saliva, because it is unclear how the source can accumulate multiple infections before transmitting those orally shedding multiple EBV variants to the next. As infection by EBV with the $\mathrm{Zp}-\mathrm{P}$ variant was a prerequisite for co-existence in this study, it is possible that an individual is more likely to acquire a prevalent variant, such as Zp-P, at first exposure to the virus, and then the host immunity to this variant is developed. However, part of hosts may fall short in resisting another different variant the next time. It is more 
likely that some instances of co-existence are the result of serial acquisition over time from independent sources. The host could gain multiple variants dynamically in the light of this hypothesis, but this cannot explain why coinfections harbor no more than two variants. It is plausible that the co-existence variants observed in this study may be new variants that were generated from point mutations of a pre-existing variant. However, the complex relationship between EBV variants and the host requires further investigation of other EBV-related diseases, various ethnic groups, different tissues or a study including a larger sample size.

\section{Conclusion}

In conclusion, this study described the EBV genotype profiles found in children with different EBV-related diseases. The most prevalent EBV genotypes found in Chinese children were type 1 EBV and the BZLF1 Zp-P variant. The results show that patients with the $\mathrm{Zp}-\mathrm{V} 3$ variant may have a higher risk of developing severe EBVassociated diseases.

\section{Materials and methods Study subjects}

A total of 206 whole blood samples were obtained from inpatients at Beijing Children's Hospital from 2006-2008 with an age range from 13 months to 12 years old. Blood was collected from 40 healthy control cases, 88 individuals diagnosed with IM, 46 with EBV-HLH and 32 with CAEBV based on their respective diagnostic criteria in previously literatures $[19,11,20]$. Genomic DNA was obtained from whole blood samples using a whole blood genomic DNA isolation kit (Tiangen, China). All the subjects were confirmed EBV-positive by conventional PCR or real-time PCR on DNA isolated from the peripheral blood leukocytes (PBL). Patients were categorized as having IM, EBV-HLH and CAEBV based on meeting the respective diagnostic criteria. The healthy control cases were enrolled on the basis of EBV-specific antibodies present in their blood detected by serologic tests for capsid antigens (CA) (Biochip; Euroimmun, Germany) but did not exhibit any clinical manifestation of EBVrelated diseases.

All individuals in the present study are of Han descents and provided informed written consent to perform the study. All procedures were approved by the Committee of Human Studies at the Beijing Children's Hospital affiliated with the Capital University of Medical Sciences.

\section{EBNA2 and EBNA3C subtyping to define of type 1 and type 2 EBV}

The determination of EBV type 1/type 2 infections was performed using a standard PCR assay across type-specific regions of EBNA2 and EBNA3C gene using primers for EBNA2: 5'-AGGCTGCCCACCCTGAGGAT-3' and 5'-GCCACCTGGCAGCCCTAAAG-3' and primers for EBNA3C: 5'-AGAAGGGGAGCGTGTGTTGT-3' and 5'GGCTCGTTTTTGACGTCGGC-3', as previously described $[21,22]$. The reaction mixture $(50 \mu \mathrm{L})$ was preincubated at $95^{\circ} \mathrm{C}$ for 5 min prior to thermocycling for 35 cycles at $95^{\circ} \mathrm{C}$ for $45 \mathrm{~s}, 56^{\circ} \mathrm{C}$ for $45 \mathrm{~s}, 72^{\circ} \mathrm{C}$ for $1 \mathrm{~min}$ followed by extension at $72^{\circ} \mathrm{C}$ for $10 \mathrm{~min}$. PCR products were analyzed by electrophoresis migration in $2 \%$ agarose gel. PCR products amplified by EBNA2 primers yield a product of 168 base pairs (bp) for type 1 EBV and $184 \mathrm{bp}$ for type $2 \mathrm{EBV}$. PCR products amplified with EBNA3C primers yield a product of $153 \mathrm{bp}$ for type $1 \mathrm{EBV}$ and 246 bp for type $2 \mathrm{EBV}$.

\section{BZLF1 Zp sequence analysis}

The $\mathrm{Zp}$ genotype was investigated based on the sequence diversity between positions -211 to +12 (with reference to the transcription start site) of the BZLF1 promoter zone (Zp) by a single step PCR. Oligonucleotide primers (5'AGCATGCCATGCATATTTC-3' and 5'-TTGGCAAGG TGCAATGTTT-3') were used to amplify genomic DNA extracted from PBL samples by PCR, as previously described before [8]. The reaction mixture $(50 \mu \mathrm{L})$ was incubated at the thermocycling conditions of $5 \mathrm{~min}$ at $95^{\circ} \mathrm{C}, 35$ cycles of $45 \mathrm{~s}$ at $95^{\circ} \mathrm{C}, 45 \mathrm{~s}$ at $57^{\circ} \mathrm{C}$ and $60 \mathrm{~s}$ at $72^{\circ} \mathrm{C}$, followed by a final extension cycle of $10 \mathrm{~min}$ at $72^{\circ} \mathrm{C}$. PCR products were separated by $2 \%$ agarose gel electrophoresis and purified. The products were used for direct sequencing with the same primers used for amplification. The EBV-positive cell line, B95.8, was used as a positive control to confirm or identify $\mathrm{Zp}$-variants.

\section{Statistical analysis}

Statistical analysis was performed using the SPSS (Version 11.0; SPSS, Chicago, USA) software package. The association of each polymorphic $\mathrm{Zp}$ with type 1 and 2 EBV and the distribution of the variants within different categories were analyzed using the chi-square analysis. All statistical tests were two-sided and $P$-values less than 0.05 were considered statistically significant.

\section{List of abbreviations}

CA: capsid antigens; CAEBV: chronic active EBV infection; EBV: Epstein-Barr virus; EBNA: EBV nuclear antigen; EBV-HLH: EBV-associated hemophagocytic lymphohistiocytosis; IM: infectious mononucleosis; PCR: polymerase chain reaction.

\section{Competing interests \\ The authors declare that they have no competing interests.}

\section{Authors' contributions}

YKJ carried out most of the studies and drafted the manuscript. GL and SY participated parts of the studies and writing. ZDX and KLS provided consultation 
and preparation of the final report. All authors read and approved the final manuscript.

\section{Acknowledgements}

We wish to express our thanks to the research project sponsored by the Fund of Capital Medical Development and Research (2007-2062) from the Beijing municipal government. We thank the staff of Virology laboratory in Beijing Children's Hospital for collecting the samples used in these studies.

\section{Author Details}

'Department of Infection, Beijing Children's Hospital, The Capital Medical University, Beijing 100045, China, 2Department of Virology, Beijing Children's Hospital, The Capital Medical University, Beijing 100045, China and 3 Department of Hematology, Beijing Children's Hospital, The Capital Medical University, Beijing 100045, China

Received: 30 March 2010 Accepted: 10 May 2010

Published: 10 May 2010

\section{References}

1. KieffE, Liebowitz D: Epstein-Barr virus and its replication. In Virology 2nd edition. Edited by: Fields BN, Knipe DM, Chanock RM, Hirsh MS, Melnick JL, Monath TP, Roizman B. New York, N.Y: Raven Press, Ltd: 1990:1889-1920.

2. Rickinson AB, Kieff E: Epstein-Barr virus. In Fields virology Volume 2. 4th edition. Edited by: Knipe DM, Howley PM. Philadelphia: Lippincott. Williams \& Wilkins; 2001:2575-2627.

3. Dambaugh $T$, Hennessy $K$, Chamnankit L, Kieff E: U2 region of EpsteinBarr virus DNA may encode Epstein-Barr nuclear antigen 2. Proc Natl Acad Sci USA 1984, 81:7632-7636.

4. Sample J, Young L, Martin B, Chatman T, Kieff E, Rickinson A: Epstein-Barr virus types 1 and 2 differ in their EBNA-3A, EBNA-3B, and EBNA-3C genes. J Virol 1990, 64:4084-4092.

5. Chen $\mathrm{HL}$, Lung ML, Chan $\mathrm{KH}$, Griffin BE, Ng MH: Tissue distribution of Epstein-Barr virus genotypes. J Virol 1996, 70:7301-7305.

6. Buck M, Cross S, Krauer K, Kienzle N, Sculley TB: A-type and B-type Epstein-Barr virus differ in their ability to spontaneously enter the lytic cycle. J Gen Virol 1999, 80:441-445.

7. Brooks JM, Croom-Carter DS, Leese AM, Tierney RJ, Habeshaw G, Rickinson AB: Cytotoxic T-lymphocyte responses to a polymorphic Epstein-Barr virus epitope identify healthy carriers with coresident viral strains. J Virol 2000, 74:1801-1809.

8. Gutierrez MI, Ibrahim MM, Dale JK, Greiner TC, Straus SE, Bhatia K: Discrete alterations in the BZLF1 promoter in tumor and non-tumor associated Epstein-Barr virus. J Natl Cancer Inst 2002, 94:1757-1763.

9. Martini M, Capello D, Serraino D, Navarra A, Pierconti F, Cenci T, Gaidano $G$, Larocca LM: Characterization of variants in the promoter of EBV gene BZLF1 in normal donors, HIV-positive patients and in AIDS-related lymphomas. J Infection 2007, 54:298-306.

10. Hamblin TJ, Hussain J, Akbar AN, Tang YC, Smith JL, Jones DB: Immunological reason for chronic ill health after infectious mononucleosis. BrMed J 1983, 287:85-88.

11. Henter J, Horne A, Arico M, Egeler RM, Filipovich AH, Imashuku S, Ladisch S, McClain K, Webb D, Winiarski J, Janka G: HLH-2004: Diagnostic and therapeutic guidelines for hemophagocytic lymphohistiocytosis. Pediatr Blood Cancer 2007, 48:124-131.

12. Okano M, Kawa K, Kimura H, Yachie A, Wakiguchi H, Maeda A, Imai S, Ohga S, Kanegane H, Tsuchiya S, Morio T, Mori M, Yokota S, Imashuku S: Proposed guidelines for diagnosing chronic active Epstein-Barr virus infection. Am J Hematol 2005, 80:64-69.

13. Christensson B, Braconier JH, Winqvist I, Relander T, Dictor M: Fulminant course of infectious mononucleosis with virus-associated hemophagocytic syndrome. Scand J Infect Dis 1987, 19:373-379.

14. Imashuku S: Differential diagnosis of hemophagocytic syndrome: underlying disorders and selection of the most effective treatment. Int J Hematol 1997, 66:135-151.

15. Ross CW, Schnitzer B, Weston BW, Hanson CA: Chronic active EpsteinBarr virus infection and virus-associated hemophagocytic syndrome. Arch Pathol Lab Med 1991, 115:470-474.

16. Tong JHM, Lo WK, Au FWL, Huang D, To Re K: Discrete alterations in the BZLF1 promoter in tumor and non-tumor-associated Epstein-Barr virus. J Nat/ Cancer Inst 2003, 95:1008-1009.
17. Chen ML, Tsau CN, Liang CL, Shu CH, Huang CR, Suliltzeanu D, Shih TL, Chang YS: Cloning and characterization of the latent membrane protein (LMP) of a specific Epstein-Barr virus variant derived from the nasopharyngeal carcinoma in the Taiwanese population. Oncogene 1992, 7:2131-2140.

18. Hu LF, Zabarovsky ER, Chen F, Cao SL, Ernberg I, Klein G, Winberg G: Isolation and sequencing of the Epstein-Barr virus BNLF-1 gene (LMP1) from a Chinese nasopharyngeal carcinoma. J Gen Virol 1991, 72:2399-2409.

19. Craigs D, Thmas C, Shigeru T: Diagnosis of Epstein-Barr virus-associated diseases. Cri Rev Onc 2002, 40:37-38.

20. Kimura H, Hoshino Y, Kanegane H, Tsuge I, Okamura T, Kawa K, Morishima $\mathrm{T}$ : Clinical and virologic characteristics of chronic active Epstein-Barr virus infection. Blood 2001, 98:280-286.

21. Khanim F, Yao QY, Niedobitek G, Rickinson AB, Young LS: Analysis of Epstein-Barr virus gene polymorphisms in normal donors and in virusassociated tumors from different geographic locations. Blood 1996, 88:3491-3501.

22. Kingma DW, Weiss WB, Jaffe ES, Kumar S, Frekko K, Raffeld M: Epstein-Barr virus latent membrane protein-1 oncogene deletions: Correlations with malignancy in Epstein-Barr virus-associated lymphoproliferative disorders and malignant lymphomas. Blood 1996, 88:242-251.

doi: 10.1186/1743-422X-7-92

Cite this article as: Jin et al., Characterization of variants in the promoter of BZLF1 gene of EBV in nonmalignant EBV-associated diseases in Chinese children Virology Journal 2010, 7:92

\section{Submit your next manuscript to BioMed Centra and take full advantage of:}

- Convenient online submission

- Thorough peer review

- No space constraints or color figure charges

- Immediate publication on acceptance

- Inclusion in PubMed, CAS, Scopus and Google Scholar

- Research which is freely available for redistribution

Submit your manuscript at www.biomedcentral.com/submit
C) Biomed Central 